\title{
Emotion-Based Language Instruction (EBLI) as a new perspective in bilingual education
}

\author{
Reza Pishghadam ${ }^{1 *}$, Bob Adamson ${ }^{2}$ and Shaghayegh Shayesteh ${ }^{3}$
}

\author{
* Correspondence: pishghadam@ \\ um.ac.ir \\ ${ }^{1}$ Ferdowsi University of Mashhad, \\ Mashhad, Iran \\ Full list of author information is \\ available at the end of the article
}

\begin{abstract}
To speed up and facilitate the process of bilingualism or multilingualism, researchers and scholars have proposed many methods and approaches that have mostly grown out of linguistic, psychological, or sociological schools of thought. However, this field has been slow to recognise the importance of emotional capacities, particularly the ones which the learners possess while learning their mother tongue and probably carry over to their L2 learning process. Drawing on the under-researched Developmental, Individual-Difference, Relationship-Based (DIR) model of language acquisition, this paper presents Emotion-Based Language Instruction (EBLI) as a new approach to bilingual education. The relevant concepts of Emotioncy, Emotionalization, and Inter-emotionality are introduced before the paper concludes by making suggestions as to how the applications of DIR to bilingual education might improve second/foreign language learning and teaching.
\end{abstract}

Keywords: Emotion-based language instruction; Emotionalization; Emotioncy; Inter-emotionality; DIR; Functional emotional theory

\section{Introduction}

Bilingualism is not only a worldwide phenomenon, it is also a reality which has occurred since the onset of language in human history (Grosjean 1982). Bilingualism and multilingualism have been the major concerns of many language teachers and learners. Numerous and diverse methods and approaches have been advanced at various points in time as more effective and efficient ways of teaching and learning languages. Stern (1983) comments that the evolution of language teaching has a convoluted history. Likewise, Brown (1994) portrays the emergence of different trends as the "changing winds and shifting sands of language teaching" (p. 52).

An overview of bilingual education reveals that methods and their underpinning theoretical principles have their origins in different linguistic and psychological conceptions (Adamson 2005, Brown 2007). For instance, the grammar translation method was followed by the idea of direct method and subsequently audiolingual method (Richards and Rodgers 2001). Research into the first language (L1) acquisition led to the development of the natural approach and total physical response. The humanistic tradition produced community language learning and suggestopedia, while communicative language teaching stressed communicative proficiency (LarsenFreeman 2000; Richards and Rodgers 2001), before the idea of a super-method was questioned (Kumaravadivelu 1994; Richards and Rodgers 2001).

(c) 2013 Pishghadam et al.; licensee Springer. This is an open access article distributed under the terms of the Creative Commons Attribution License (http://creativecommons.org/licenses/by/2.0), which permits unrestricted use, distribution, and reproduction in any medium, provided the original work is properly cited. 
Manifestly, the desire for communication has been a cogent motivation for efforts to improve the development of bilingual and multilingual competence. One source of inspiration has been comparisons of L1 and L2 learning. However, this field has perhaps been slow to recognise the importance of emotional capacities, particularly the ones which the learners possess while learning their mother tongue and probably carry over to their L2 learning process. Although humanism has stimulated the formulation of a few pertinent approaches, the emotional aspect of language learning has largely remained peripheral. This paper seeks to address this imbalance by focusing on the emotions learners bring to their L2 learning from their L1 experiences. The paper draws upon Greenspan (1992) idea of a functional emotional approach and the Developmental, Individual-Difference, Relationship-Based model (DIR) in L1, we apply his concepts and analytical framework to the realm of L2 teaching and learning and bilingual education, and suggest that this approach may enlighten some tenebrous aspects of language learning. In the paper, we introduce the Emotion-Based Language Instruction (EBLI) model, focusing specifically on emotioncy, emotionalization, and inter-emotionality. To do so, we first review language acquisition theories, then we present the Greenspan (1992) theory on language, and finally we apply the theory to L2 studies.

\section{Language acquisition}

The idea of language acquisition has long occupied the minds of philosophers, linguists, and psychologists. Behaviorist proponents argued that language acquisition occurs through repeated successful associations made between stimulus and response (Hutchinson and Waters 1987). On the other hand, nativists believed that language acquisition is governed by an innate universal grammar which genetically determines the process of acquisition (Brown 1994). Early attempts to establish a non-nativist outlook on a child's language acquisition concentrated on the frequency of use for first acquired words and their semantic complexity (Nelson 1977). Afterwards, usage-based theorists (e.g., Tomasello 2003) proposed that saliency is a noteworthy element. From a different perspective, Greenspan and Shanker (2004) argued that it is affect that prevents the social cognitive approach from falling back into a nativist's paradigm. Furthermore, affective experience is the critical missing fragment which determines word saliency for a child in the usage-based aspect. Thus, a word like "mommy" is learned not only based on its high frequency, but also on the emotions (joy, love, satisfaction, etc.) that are associated with the word. Similarly, "apple" is not simply a fruit that is round and red; it conveys the notion of an enjoyable snack for many people since it is sweet, juicy, and crunchy (Greenspan and Shanker 2004).

Overall, from a historical point of view, language learning can be categorized into three chief movements: behavioristic, cognitive, and social (Brown 2007). The emotional movement, which we examine more closely in this study, is a new addition to this list.

\section{Behavioristic movement}

Building on the work of Pavlov (1927) and Skinner (1957), language development can be seen as the result of a set of habits (Hutchinson and Waters 1987). Beginning in the 1950s, behaviorism moved from the arena of psychology to education. Schooling practices started to center around the notion that if teachers provide the correct 
stimuli, the learners not only learn but their learning can be measured through observation of their behaviors. This approach considered teachers responsible for students' learning. That is, if the process of learning was not successful the teachers were required to restructure the environment, identify the most suitable stimuli to obtain the needed behavior, or create negative reinforcement to quench undesirable behaviors (Jones and Brader-Araje 2002).

\section{Cognitive movement}

As a new approach to teaching and learning, cognitivism emerged during the 1970s in response to the inability of behaviorism to account for aspects of language learning. Unlike behaviorists, cognitivists deemed language learning a conscious and reasoned thinking process, and language learners as active processors of information (Ausubel et al. 1978). A key notion was that of students' engagement with instructional materials as a major contributor to their own language learning. The teachers were to provide an effective environment along with a rich context of authentic language for students to negotiate meaning and develop strategies for language discovery (Anderson 1985). In response, students would combine their prior knowledge with the new language input to construct and reconstruct meaning.

\section{Social movement}

Towards the end of the 20th century and the beginning of the $21^{\text {st }}$ century, socio-cognitive or social approaches toward language education attracted attention. Their main focuses were the concepts of social interaction and learning as an active process involving others and many aspects of society (Atkinson 2002). The basis was the work of Bakhtin (1981), Vygotsky (1986), and Bruner (1983), who underlined the interactive dimension of educational work and its impact on linguistic development. Authentic learning is notably effective since the students are in contact with real world applications of language. A particular revolutionary element of this movement is the role of a teacher, which changes from an information transmitter to a facilitator or a guide (Meyer 2009) as the students engage in cooperative learning activities.

\section{Emotional movement}

Since the establishment of psychoanalysis, a number of leading practitioners have highlighted the significance of emotion on learning, thought, and education (Bowlby 1952; Freud 1911; Murphy 1974; Rappaport 1960). Freud (1911) compared emotions to a wayward horse controlled by the rational ego. In contrast, Greenspan and Wieder (1998a) argue that emotions support our actions, experiences, behaviors, and thoughts.

Investigations into the role of emotional factors in second/foreign language learning and teaching are not a novel phenomenon. Several methodologies, such as suggestopedia, have addressed emotional and psychological notions, motivated in some cases by Krashen's claim of a language monitor and his affective filter hypothesis (Pishghadam 2009). Nevertheless, the emotional aspect is still peripheral in many educational systems (Shanmugasundaram and Mohamad 2011) and cognitive abilities are considered as the sole predictors of academic achievement (Moraru et al. 2011). However, the significance of emotion gained increasing recognition in education during the 1980s and 1990s 
(Tormey 2005), with the most popular reflection of this trend being Gardner's (1983) Multiple Intelligences (MI) (shades of the emotional domain represented in his work on intrapersonal and interpersonal intelligences). Then, the term Emotional Quotient (EQ) was introduced by Bar-On (1988) as a counterpart to Intelligence Quotient and cognitive ability. According to Bar-On (1988), EQ comprises a set of social and emotional abilities to help individuals with their daily life. Salovey and John (1990) adopted a different perspective and propounded Emotional Intelligence (EI) as the "ability to monitor one's own and other's feelings and emotions, to discriminate among them, and to use this information to guide one's thinking and action” (p. 189). In 1995, Goleman published his book "Emotional Intelligence" and popularized the concept (Goleman 1995). He saw EI as arising from a large set of research findings on the role of emotions in life. One of those theories dealing with emotion is Greenspan's (1992) ideas on the relationship between language and emotion. In the next section, we review this theory, which has been given little attention in language studies.

\section{Greenspan's theory}

Greenspan (1992) stresses the importance of the missing link of emotion by challenging the basis of previous methodologies. Refuting Chomsky (1966), he claimed that symbols, language, and intelligence are not deeply rooted in genetics; instead, they evolve out of the emotional responses gained by means of the child's interaction with the environment and other human beings. In comparison with Freud (1911), Greenspan (1992) gives more weight to the role of emotional experiences in the development of the child's early functional and social improvement. In a slight variation from Vygotsky's (1978) principle of the Zone of Proximal Development (ZPD), in which the adult takes the lead in the unequal interaction and provides instructive correction to a child performing a set of tasks, Greenspan's proposed interactions are more child-directed. This outlook bears some superficial similarities to Bruner's (1983) concept of "format", although Bruner's format hinges on the child and caregiver's engagement in activities such as dressing, bathing, or playing which involve both language and culture; in fact, the two are meaningfully inseparable. Furthermore, unlike Greenspan's developmental interactions, formats may either carry a special purpose or simply be performed as an amusement tool (Bruner 1983).

Contrary to the traditional concept of development which separates affect from intellect, Greenspan (1992) posits that emotions play a critical role in improving the intellectual faculties. Given the paramount role of emotional interactions in cognitive functioning, Greenspan went beyond the previous observations of the time. He synthesized various insights and added the key concept of emotional development as the essence of his vision. According to his view, language, as a substantial cognitive process, does not occur suddenly at some pre-determined manner; instead, it emerges out of the child's interaction with his parent or caregiver in co-regulated activities, namely playing, sharing, and naming.

\section{Functional emotional theory}

In 1997, Greenspan set forth a theory of a process through which functional emotional approaches create and organize various aspects of the mind and intelligence. As the 
term suggests, the theory mainly stems from an amalgam of two common notions of 'functions' and 'emotions'. Several attempts have been made to catalogue the different functions of language found in the growing child's repertoire. Children are motivated to acquire a language since it serves particular purposes or functions for them. In this realm, Halliday's (1975) taxonomy focuses on some functions which help children to fulfill their physical, emotional, social, and environmental needs-the emotional dimension of the theory largely originates from the idea of emotional competency and EQ which was discussed earlier.

As Greenspan (1997) states, affective signals are the primary concepts we use to experience the world, and they emerge prior to the sensorimotor patterns presented by Piaget (1962). Moreover, he showed that intellect, academic abilities, consciousness, and morality are rooted in our earliest emotional experiences (Greenspan and Shanker 2004). The crux of this approach to language development is that language skills evolve from a sequence of affective transformations, which make the child initially self-regulate and get interested in the world, and subsequently, following a series of further transformations, take part in the social interactions, become involved in shared attention, recognize social, communicative patterns, figure out other people's intentions, imitate complex actions, form a sense of 'self', and create meaningful symbols (Greenspan and Lewis 2005). Basically, the child nourishes these underlying capacities and gradually moves from the pre-symbolic stage to language.

When the ability to form symbols evolves in children, they are required to harness their inner affects to symbols to produce meaningful notions such as language, imagination, and logical thought. In other words, the affect-mediated interactions enable children to perceive the patterns of the world through symbols, and eventually transform these patterns to thought and conversation (Greenspan 2001). Gestural and social interactions provide the context for the meaning of verbal symbols. The necessity of this fundamental level of knowing through doing is highly emphasized in the gradual process of meaning formation. Children move from global affective schemes to reciprocal ones. Long chains of affective interactions enable children to further explore the world based on the received feedback and to organize gestural or verbal communication. In essence, affect assists children to go through the simple interest in the world toward social problem-solving, and advance through procedural knowledge to symbolic knowledge. It gives meaning to what children hear, how they process the visual-spatial information, and arrange motor activities (Greenspan 2001).

As children begin to imitate words (mom, dad, go), those words have to be flavored with affect to hold meaning. The word "juice" has meaning to the extent the child can combine it with different feeling experiences including the pleasure and image of drinking juice (Greenspan 2001). In truth, to feel an emotion, it is necessary to experience that emotion in a consistent relationship; that is to say, it is not possible to experience the emotions which we have never had (Greenspan and Lewis 2005).

However, emotional experiences are not restricted to semantics only; they can likewise be applied to children's learning of grammar. For instance, the word "more" might not denote quantity for children, but rather remind them of something tasty; whereas, "no more" could remind them of a dose of bitter medicine. "Big" is an older child who is walking around and "little" is a baby of his own age and size (Shanker and Greenspan 2005). During speech language therapy sessions, the therapists may 
attempt to teach preliminary grammatical forms by repeatedly drilling the child on some particular structures that may turn to be exhausting for both the child and therapist. Here, the main issue is that the structure has been emphasized with no regard to the emotional aspect. Unlike the therapist, the caregivers act more effectively and teach that same structure by using affect gestures and slightly varying their tone of voice, by uttering "gentleeee" (Greenspan and Shanker 2004; Shanker 2002) for instance.

\section{DIR}

In order to facilitate the reciprocal affective processes, a social pragmatic approach was proposed by Greenspan (1997). DIR, a theoretical and applied framework for comprehensive, individually-determined intervention, integrates the child's isolated functional developmental capacities (social, motor, cognitive, language, and sensory) that lay the foundation for higher order thinking and purposeful communicating (Greenspan 1992; Greenspan and Wieder 1998a). This treatment technique was initially designed to help disturbed children suffering from autism. To define the core components of this multidisciplinary approach, the " $\mathrm{D}$ " represents the developmental capacities including mutual attention and engagement, back and forth interactions, affective reciprocity, problem-solving, creating play ideas, and abstract thinking which appear during the child's early years. This component indicates six functional developmental features: 1) self-regulating and processing environmental information, 2) involvement in a relationship, 3) maintaining and responding to a mutual purposeful communication, 4) making complex gestures and directing the communication toward problem-solving, 5) creating and deploying ideas, and 6) making a link between ideas, reality, and thought. There is a plenty of evidence which shows that emotional processes including engagement, joint attention, affective reciprocity, and creative play are related to healthy social, language, and intellectual functioning (Greenspan 2004; Siller and Sigman 2002).

The "I" represents the child's individual differences in sensory motor processing and regulation which support development. The " $R$ " represents the relationships and environment required for the interactions through which the development of emotional, social, and cognitive capacities is fostered (Greenspan and Wieder 2006).

Central to the DIR model is the secure relationship which promotes spontaneous sequences of back-and-forth affect cues between the parent and child to help the child expand and elaborate upon ideas, thoughts, and feelings and overcome the probable developmental challenges of linking up emotions to motor planning and verbal communication (Seskin et al. 2010; Wieder and Greenspan 2003). The very intention is to empower every single developmental capacity, which jointly can set the basis for higher order abilities (Greenspan and Wieder 2006). The intervention approach, which is built on the child's and family's unique developmental profile, involves parents, caregivers, or teachers in developing a better understanding of their child using the complex verbal or gestural interactions between biology and experience. In fact, it enables them to enter the child's world, bring the child into a joint world, make a communication bridge, and interact with the child in ways that nurture emotional, social, and intellectual development (Greenspan 2001). Thus, more and more emotions 
must be injected into the interactions. Once the interactions become more captivating and meaningful, the child progresses much faster and easier. As a result, the adult's emotional interest, that is brought to the context, must rise as the task gets harder (Greenspan and Lewis 2005).

Overall, the model highlights the necessity of unifying family support, school programs, home programs, biomedical mediation, and other required therapies tailored to meet children's entire needs and goals, into their intervention schedule (Greenspan 2001). To this end, Greenspan and Wieder (2006) recommend running various types of interactions in multiple different settings and environments to help the children progress through the developmental stages more purposefully.

\section{The floor time therapy}

The model's major intervention constituent is "Floor Time", a non-directive, relationshipbuilding play therapy for parent and children with autism spectrum disorders (Greenspan and Wieder 2006). It is mostly aimed at infants, toddlers, and preschoolers, but might be utilized for older children if necessary. Play is an integral part of child development. During floor time daily play sessions, adults sit on the floor with the children and follow their lead using gestures and words to move the children up the symbolic ladder and help them enter the world of ideas and abstract thinking (Wieder and Greenspan 2003). Messina (1999-2004) considers that Floor Time encompasses five successive steps: 1) observation, 2) the child opens the communication circle, 3) the adult follows the child's lead and interest, 4) they extend and expand play, and 5) the child closes the communication circle. The flow of interactions allows many circles of communication to be opened and closed in expeditious sequences. During this course, the child realizes and savors the concept of two-way communication (Messina 1999-2004). The play framework supports engagement, symbolic play, problem-solving, friendship, and higher order thinking (Greenspan and Wieder 2005). In a study, Greenspan and Wieder (1998b) examined a cohort of 200 children between the ages of 22 months and 4 years diagnosed with autism spectrum disorders and concluded that most children (58 \%) who received Floor Time intervention for at least 2 years made notable progress in all areas of development. All the children of the study received two to five hours of Floor Time interaction along with speech therapy and educational services. Years later, in 2005, Greenspan and Wieder set out a 10-15 year follow-up on 16 children of their former case review. The final outcome manifested that the participants were particularly strong in levels of empathy and theory of mind tasks, and were able to successfully relate their thoughts, ideas, and intentions to themselves and others. Simply put, the children could progress out of their deficits and autism symptoms, and develop into individuals with a typical, hopeful future (Greenspan and Wieder 2005). In all, the majority of the studies which have inspected DIR/ Floor Time have reported numerous benefits of the intervention (Simpson 2005).

\section{DIR and second language pedagogy}

The methodological core of the DIR model is to appreciate the role of affect and the importance of supportive relationships and family functioning (Greenspan 2001). Although DIR is a model of first language acquisition, each of its components also has deep historical roots in second language learning and teaching. 


\section{Developmental perspectives}

Developmental perspectives have been broadly taken into account in second language as well as the first language learning procedures. Studies have shown that both first and second language learners go through a pattern of development (Ipek 2009). This enterprise represents the basis for several approaches to SLA. Rod Ellis (1984) discusses and outlines the concept of developmental sequences in detail. Pienemann's processability theory (Pienemann 1998, 2005) is a theory of language development, which predicts a universal and developmental hierarchy for any given first or second language. Krashen's (1982) Input Hypothesis attempts to explain the way acquirers move from one stage (i) to the next $(i+1)$. According to this hypothesis, learners receive comprehensible input and progress along the natural order to a step beyond their current level of competence and knowledge.

\section{Individual differences}

A thorough recognition of individual differences is substantial to discover the factors that influence learning development and the mechanisms involved (Astington 1993; Cutting and Dunn 1999). Research into the effects of individual differences on learning is well established in the fields of first and second language acquisition. For instance, McLaughlin (1987) posits that considerable individual variation in learning, performance, and communication strategies results in diversities in learning processes. It has long been witnessed that there is a broad discrepancy among language learners with respect to their ultimate success in mastering an L2 (Dornyei 2005). With ongoing developments in the study of motivation, personality, and different cognitive abilities of learners, individual differences remain a powerful area in the educational contexts (Dornyei 2005). Individual differences, as consistent predictors of learners' success, have been studied widely within L2 domain, turning the field into one of the most thoroughly studied aspects of SLA. Controversial issues for a discussion of the broad scope of individual learner differences in second language learning include cognitive variables (such as aptitude, learning styles, and strategies), affective variables (such as motivation, self-efficacy, and anxiety), personality traits, culture, gender, etc.

\section{Relationship-based perspectives}

In both first and second language acquisition a rich linguistic environment contributes to successful language development. Based on this premise, applied linguistics critically highlights the significant role of interaction in SLA (Long 1996; Tomasello 2003). Relationship-based or interactionist approaches toward language acquisition centre around a one-to-one interaction constructed via exchanges of comprehensible input and output which gives the child access to language (Ipek 2009). Krashen's (1982) theory, mentioned above, promotes SLA and fluency through one-way comprehensible input. Others take an interactionist position emphasizing a two-way communication. Long (1985) believes that conversational interaction is influential on SLA. Hawkins (2001) argues that, by means of interactions such as collaborative activities, pair work, and group work, knowledge is gradually constructed. A further issue related to the L1 and L2 acquisition is the ZPD. Vygotsky (1978) explains ZPD as a child's learning capacity when collaborating to negotiate meaning. Meanwhile, interactional modifications effectively simplify the input for the second language learner (Ellis 1994; Long 1996). 
Overall, fashions in language learning theories have come and gone, each setting forth hypotheses on how we generally learn, and how we might teach languages. We have argued that the critical missing piece in the SLA domain is the investment of affect, which was proposed by Greenspan (1992). We label this new perspective as Emotion-Based Language Instruction (EBLI).

\section{Emotion-based language instruction}

Although students of a foreign language class are exposed to shared instructions and lessons, each individual may undergo a unique learning experience (Garrett and Young 2009). As noted earlier, emotions may be the result of individuals' idiosyncratic reactions to people, objects, or words, meaning that a person who has been bitten by a dog might closely associate the word "dog" with fear; whereas, the person who has been grown up with a gentle dog may hold more positive emotions toward this specific word. Generally, emotional reactions are not created by the language itself, but by the experiences conveyed alongside with them and the people who use them. In fact, it is through experiencing the world and providing affective responses to these experiences that individuals develop their unique sense of preference or abhorrence (Garrett and Young 2009).

\section{Emotionalizing language}

The major objective of this paper is to stress emotional capital and to suggest a different outlook toward L2 learning. Most children have the capacity and facility to learn more than one language. Largely inspired by Greenspan and his model of DIR, our hypothesis is based upon a pair of underlying premises: a) that effective emotional interaction of a learner with his teacher, and b) emotionalizing language (Pishghadam et al. 2013) lead to better L2 learning. The former premise mainly revolves around humanistic psychology and EI, while the latter premise hinges on building emotions toward L2 lexical items. As the premise implies, children acquire their mother tongue while interacting emotionally with their parents. To be specific, words have meanings and meanings are conveyed through the emotional context (world) in which the word is utilized (Greenspan 2001). That is to say, throughout first language acquisition, "word" (semantic aspect of language) and "world" (pragmatic aspect of language) are acquired simultaneously. The newly-acquired word takes on additional meaning from the context and further emotional experience with it (Greenspan 2001). In contrast, during the process of L2 learning the child already owns the "world" information transferred from L1 and only lacks the pertinent "word". Thus, in the first place, children are likely to learn the words which are equivalent to their L1 vocabulary list. The groundwork of this stage is to draw linkage between L1 and L2 lexical words. When the learners are able to connect emotionally with the information, it produces deeper meanings and stronger ties to previous knowledge (LeDoux 1996). Simply put, if a child encounters a word which has little or no emotional association, then language learning procedure becomes cumbersome (Pishghadam et al. 2013).

\section{Emotioncy}

To better illustrate our hypothesis, we proceed with an example of an eight-year-old child learning a number of English words (Figure 1). He learned the words in the following order: 


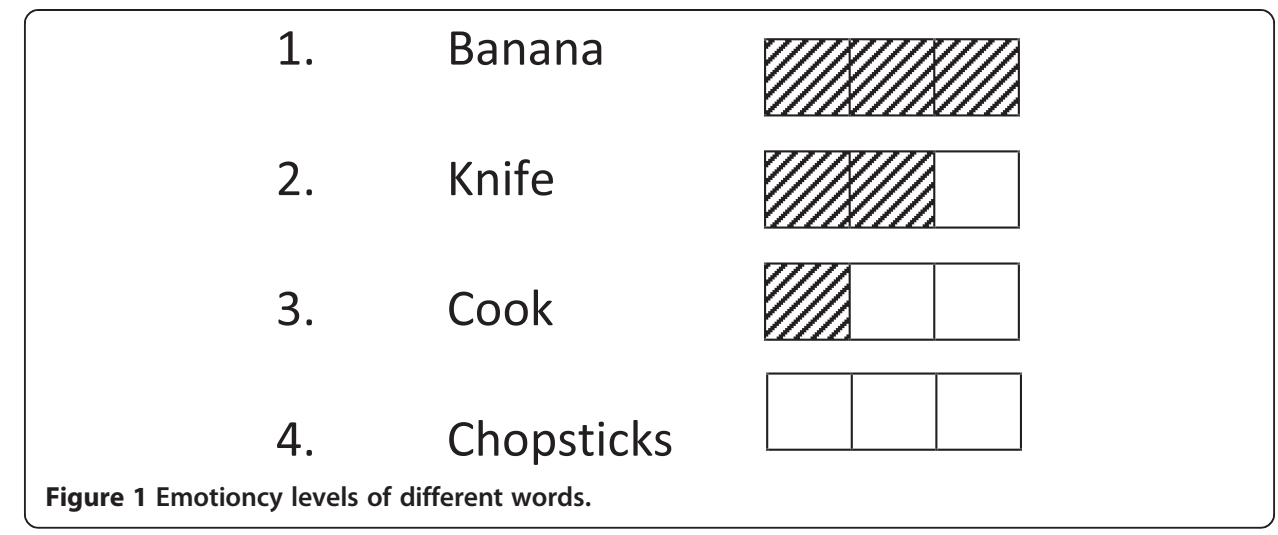
1. Banana
2. Knife
3. Cook
4. Chopsticks

As the order suggests, the child has learned the words toward which he had more emotion and afterwards the ones holding less emotion. Based on the EBLI, each entity carries a degree of emotion for individuals, which we refer to as emotioncy. It means that, the words with higher degree of emotion are learned faster and easier compared to the ones with a lower degree of emotion. The following figure illustrates the emotioncy of the aforementioned words.

Based on the figure, in the above example, the boy has stronger emotions for the word "banana", since he has tasted, smelled, and touched that fruit. Besides, he has seen and touched a "knife" but has not used that himself. That's why this word is located second in the learning order. Concerning the word "cook", the child has only observed the action without experiencing it; and in terms of "chopsticks" the child has neither seen nor used these tools, and therefore has no emotion toward the word.

\section{Emotionalization}

Throughout the years, L2 practitioners have presented several criteria for vocabulary teaching. For example, Widdowson (2004) deemed frequency, coverage, and prototype as noteworthy features. According to him, frequency information is strongly beneficial in helping to prioritize what to teach. Coverage relies on its degree of semantic resemblance upon which a word can be used to replace other words. And prototypes are words and structures that are likely to be included as pedagogically core or nuclear at a specific stage with respect to their actual occurrence in contexts of use.

We believe that, emotioncy is equally able to determine the salience of a word and serve the purpose of a worthwhile benchmark for vocabulary teaching (Pishghadam et al. 2013). In this vein, what gains importance is the matter of localization. Emotions vary between cultures, regions, and languages. To be specific, individuals coming from different regions, social classes, and cultural backgrounds are probably acquainted with certain types of words and hold stronger emotions for them. For instance, within the Iranian context, on account of geographical diversities, a child coming from the northern 
regions of the country is more profoundly and emotionally familiar with the word "jungle" than a child living in southern regions. Also, a child from the upper social class is better familiar with the word "Xbox" than a friend from the lower social class.

Our argument is that, it is effective if we advance beyond pure and conventional contextualization, magnify the role of lexical emotions, and move toward emotionalization in the second language teaching domain. Meanwhile, it is recommended to employ the words toward which the learner has little or low emotion with more consideration and in proper situations (Pishghadam et al. 2013). According to Pishghadam et al. (2013) it seems that, de-emotionalization surpasses de-contextualization; given that as long as the learner does not establish an emotional relationship with the text, one is not able to reach a full understanding. Imagine a girl who was born in Iran. Based on the Islamic ambiance of the country she is not emotionally informed of words such as "bar", "drink", and "wine". Accordingly, she probably learns the words of this type with difficulty.

Furthermore, emotionalization goes beyond Piaget's (1926) schema theory, which argues that human beings own categorical rules or scripts to interpret and predict the world. Therefore, information is analyzed and comprehended based on how it accords with these rules. The most indispensable aspect of schema theory is the role of prior knowledge in information processing; while emotionalization shifts the focus and underscores the crucial role of prior emotion.

Furthermore, contrary to Krashen's ( $\mathrm{i}+1$ ) hypothesis (1982) that second language acquirers grasp input which is one step beyond their current stage of linguistic competence, Pishghadam et al. (2013) firmly believe that learners best understand the input which is a little beyond their level of emotioncy. This implies that, in order to facilitate the process of language learning, learners need to be emotionally familiar with the input that is slightly above their existing level of emotioncy; at advanced levels of learning, words and the environment need to relink. Moreover, with a very few essential exceptions, the majority of the input should be words with which the learners have already established an emotional relationships in their L1.

The ultimate issue that may spark a further debate is the concept of motivation, grounded in the Piagetian hypothesis of equilibration. As cognition develops from the state of doubt and uncertainty (disequilibrium), the child remains eager and motivated to acquire the necessary language and reach the final stages of cognitive certainty and resolution (equilibrium) (Brown 2007). That is to say, disequilibrium is likely to maintain significant motivation for language acquisition. Quite the opposite holds for our word-learning theory of EBLI. As it was noted earlier, this approach demands strong emotional linkage with learners' environmental information in their L1. Consequently, due to the absence of disequilibrium the learner may not be able to perceive the knowledge gap and be motivated enough to fill it in. Thus, additional research is called for to show whether the lack of this type of motivation may hinder language acquisition, or if other sources of motivation are likely to compensate for this deficiency.

\section{Inter-emotionality}

Bilingual learners' L1 plays a significant role in the learning of L2 in terms of cognitive, linguistic, and cultural influences (Peal and Lambert 1962). There has always existed a flow between first and second language acquisition with regards to their lexicon and 
grammatical rules. However, we believe that emotions, similarly, move between the two languages-a phenomenon which we refer to as inter-emotionality.

As Figure 2 depicts, when the flow moves from L1 to L2, the learners already own the germane emotion and merely lack the language, which they then acquire. On the other hand, when the flow moves from L2 to L1, the learners lack both the language and emotion, which may hinder the acquisition process. The following examples demonstrate the issue with respect to lexical and grammatical aspects.

Example 1: Lexical

A teacher intends to teach the words "Halloween" and "Christmas" to a boy with Farsi as his L1. The question is how it is possible to create emotion for the mentioned words since the child is not familiar with these two events in his own culture. We strongly believe that, if emotion creation happens pragmatically while the child is doing something outside the academic setting such as surfing the internet, playing video games, or watching movies, learning will be more successful.

\section{Example 2: Grammatical}

A teacher intends to teach the sentence "I go to school" to a girl with Farsi as her L1. The problem that the child may encounter is that, unlike English, Farsi is a pro-drop language. Therefore, the grammatical emotion needs to be engendered for the child to realize that the pronoun is non-removable in the English language.

\section{Conclusion}

"Becoming bilingual is a way of life. Your whole person is affected as you struggle to reach beyond the confines of your first language and into a new language, a new culture, a new way of thinking, feeling, and acting" (Brown 1994, p. 1). When children develop their abilities in two or more different languages, they build up a broader understanding of language and its usage, especially when the languages are compared and contrasted (Peal and Lambert 1962).

One of the features which has been less compared and contrasted is the emotional loading of words. Since the emotion-related dimension has been recognized as a substantial construct of language education, the tendency to include learners' emotions in SLA research has grown. Moving a step forward, we have identified emotions as the driving force behind SLA and produced a fresh emotion-based insight into the semantic aspect of this territory. In essence, EBLI emerges from the heart of emotional competency and EQ. It exceeds several cognition-based assumptions of theoreticians such as Piaget (1962), Krashen (1982), Vygotsky (1978), and Long (1985), and unlike cognitive approaches which try to enter learners' brains through their cognition, EBLI tries to enter learners' brains through their hearts.

Commonlexicon and grammar
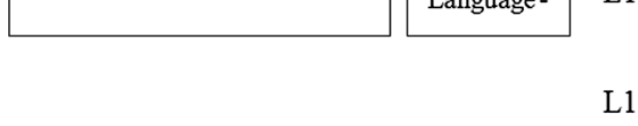

\section{L1}

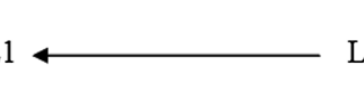

Figure 2 Inter-emotionality between words in L1 and L2. 
To sum up, this study intends to bring to light what has been concealed by opening up a new vista on the notion of DIR within the realm of bilingual education and SLA. The key to developing this insight is that lexicons are pregnant with emotion. Words have different weights; they carry emotions to a greater or lesser amount. As a result, we recognize that words are not abstract and disconnected entities employed to get our ideas across. It is of paramount importance to note that "word" and "world" are two complex, interwoven concepts, which symbiotically facilitate the development of first/ second language processes. Throughout L1 acquisition, the two concepts are acquired simultaneously as the child begins to interact with the surrounding environment. However, during the course of second/foreign language learning, the child already owns the concept of "world" transferred from the mother tongue. Thus "world" acts as a robust prerequisite for learning "word" in SLA.

In expounding our theory, we have offered three new concepts, emotioncy, emotionalization, and inter-emotionality. It is argued that a higher rate of success may be obtained when the affective salience of words is heightened. That is, the words with stronger emotioncy or degree of emotion are absorbed with less effort and trouble. Therefore, we suggested that emotioncy could regulate the salience of a word for the goal of vocabulary teaching. However, emotions are likely to differ widely from one culture to the next. In consequence, a word's load of emotion for individuals from miscellaneous regions, cultures, or languages may vary to the extent that localization becomes substantive. Thus emotionalization can be balanced with contextualization as a supplementary step toward comprehension, in that words with less emotion loads can be employed in suitable situations.

Targeting bilingual learners' emotions is likely to have a significant positive outcome on their language learning. The focus on affect and emotion might inspire materials developers to pay extra attention to learners' idiosyncratic differences and the concept of localization. Educators must pay sufficient attention to the cultural issues in the materials they provide for the learners. Also, in order to simplify student learning, materials should be organized according to the lexical items with which the students are already familiar in their L1. Although the proposed applications and implications largely address children, adults would probably enjoy the benefits, too. As children's language learning progresses, they acquire more domain-specific skills (Shanker and Greenspan 2005). By exploring the contents with which adult learners have more associations emotionally, practitioners can determine appropriate syllabi for English for Specific Purposes and ContentBased Instruction, to mention but two domains.

EBLI opens new horizons for researchers in the field, manifesting a novel orientation of dealing with bilingual and L2 learning issues. EBLI is now capable of forming new theories and providing auspicious areas of research. Study on affect and emotion of lexical and grammatical items has just started and much more research is still required to explore how this technique might work for bilinguals, teachers, and their students. 
Iran. In 2010, he was classified as the distinguished researcher in humanities by the Ministry of Sciences, Research, and Technology of Iran. His current research interests are: psychology and sociology of language education, cultural studies, syllabus design, and language testing. BA is a professor of Curriculum studies at Hong Kong Institute of Education and the director of the UNESCO-UNEVOC Centre (Hong Kong). He is currently the head of the Department of International Education and Lifelong Learning in the Institute. He publishes in the fields of English language teaching, teacher education, comparative education, curriculum studies, and higher education. His books include China's English: A History of English in Chinese Education (2004); Comparative Education Research: Approaches and Methods (coedited with Mark Bray and Mark Mason 2007); and The Reorientation of Higher Education: Challenging the East-West Dichotomy (co-edited with Jon Nixon and Feng Su 2012). SS has an MA in TEFL from the Ferdowsi University of Mashhad, Iran. She has published a few articles in national and international journals. Her current research interests are psychology and sociology of language education. All authors read and approved the final manuscript.

\section{Acknowledgements}

The authors would like to express their profound gratitude to Dr. Amir Amin Yazdi and Diane Lewis who gave us the inspiration to enter this area and carry out the research.

\section{Author details}

${ }^{1}$ Ferdowsi University of Mashhad, Mashhad, Iran. ${ }^{2}$ Hong Kong Institute of Education, Hong Kong, Hong Kong.

${ }^{3}$ Ferdowsi University of Mashhad, Mashhad, Iran.

Received: 23 September 2013 Accepted: 21 November 2013

Published: 25 November 2013

\section{References}

Adamson, B. 2005. Developing information technology for English in Chinese secondary schools. In Information technology and innovation in language education, ed. C Davison, 81-101. Hong Kong: Hong Kong University Press.

Anderson, J. 1985. Cognitive psychology and its implications. New York: Freeman.

Astington, JW. 1993. The child's discovery of the mind. Cambridge, MA: Harvard University Press.

Atkinson, D. 2002. Toward a sociocognitive approach to second language acquisition. Modern Language Journal 86(4): 525-545. http://dx.doi.org/10.1111/1540-4781.00159.

Ausubel, DP, et al. 1978. Educational psychology: a cognitive view. New York: Holt, Rinehart and Winston.

Bakhtin, MM. 1981. The dialogic imagination: four essays (trans: Caryl, Emerson, and Michael, Holquist. Austin: University of Texas Press.

Bar-On, R. 1988. The development of a concept of psychological well-being. Rhodes University, South Africa: Unpublished doctoral dissertation

Bowlby, J. 1952. Maternal health and mental health. WHO Monograph Series No. 2. Geneva: World Health Organization.

Brown, DH. 1994. Teaching by principles: an interactive approach to language pedagogy. Englewood Cliffs: Prentice Hall Regents.

Brown, DH. 2007. Principles of language learning and teaching (5th ed.). White Plains, NY: Longman.

Bruner, J. 1983. Child's talk: learning how to use language. New York: Norton.

Chomsky, N. 1966. Cartesian linguistics. New York: Harper and Row.

Cutting, AL, and J Dunn. 1999. Theory of mind, emotion understanding, language, and family background: Individual differences and interrelations. Child Development 70(4): 853-865. http://dx.doi.org/10.1111/1467-8624.00061.

Dornyei, Z. 2005. The psychology of the language learner. Mahwah, NJ: Lawrence Erlbaum.

Ellis, R. 1984. Classroom second language development. Oxford: Pergamon.

Ellis, R. 1994. The study of second language acquisition. China: Oxford University Press.Freud, S. 1911. Formulations on the two principles of mental functioning, Standardth ed. London: Hogarth Press.

Gardner, H. 1983. Frames of mind: the theory of multiple intelligences. London: Fontana.

Garrett, P, and RF Young. 2009. Theorizing affect in foreign language learning: an analysis of one learner's responses to a communicative Portuguese course. The Modern Language Journal 93(2): 209-226. http://dx.doi.org/10.1111/ j.1540-4781.2009.00857.x.

Goleman, D. 1995. Emotional intelligence. New York: Bantam Books.

Greenspan, SI. 1992. Infancy and early childhood: the practice of clinical assessment and intervention with emotional and developmental challenges. Madison, CT: International Universities Press.

Greenspan, SI. 1997. The growth of the mind and the endangered origins of intelligence. Reading, MA: Addison Wesley Longman

Greenspan, SI. 2001. The affect diathesis hypothesis: the role of emotions in the core deficits in autism and in the development of intelligence and social skills. Journal of Developmental and Learning Disorders 5: 1-46.

Greenspan, SI. 2004. Greenspan social-emotional growth chart. Bulverde, TX: The Psychological Corporation.

Greenspan, SI, and D Lewis. 2005. The affect-based language curriculum: an intensive program for families, therapists and teachers (2 ${ }^{\text {nd }}$ ed.). Bethesda, MD: Interdisciplinary Council on Developmental and Learning disorders (ICDL).

Greenspan, SI, and S Shanker. 2004. The first idea: how symbols, language and intelligence evolved from our primate ancestors to modern humans. Boston: Da Capo Press, Perseus Books.

Greenspan, SI, and S Wieder. 1998a. The child with special needs: encouraging intellectual and emotional growth. Reading, MA: Addison-Wesley.

Greenspan, SI, and S Wieder. 1998b. Developmental patterns and outcomes in infants and children with disorders in relating and communicating: a chart review of 200 cases of children with autistic spectrum diagnoses. The Journal of Developmental and Learning Disorders 1: 87-141.

Greenspan, SI, and S Wieder. 2005. Can children with autism master the core deficits and become empathetic, creative and reflective? a ten to fifteen year follow-up of a subgroup of children with autism spectrum disorders (ASD) who received a comprehensive developmental, individual-difference, relationship-based (DIR) approach. The Journal of Developmental and Learning Disorders 9: 39-61. 
Greenspan, SI, and S Wieder. 2006. Engaging autism: using the floor time approach to help children relate, think, and communicate. Cambridge, Ma: Da Capo Press.

Grosjean, F. 1982. Life with two languages: an introduction to bilingualism. Cambridge, Mass: Harvard University Press. Halliday, MAK. 1975. Learning how to mean: explanations in the development of language. London: Edward Arnonld. Hawkins, B. 2001. Supporting second language children's content learning and language development in K-5. In Teaching English as a second or foreign language, 3rd ed, ed. C-M Marianne, 367-383. USA: Heinle and Heinle.

Hutchinson, T, and A Waters. 1987. English for specific purposes: a learning-centered approach. Cambridge: CUP. http:// dx.doi.org/10.1017/CBO9780511733031.

Ipek, H. 2009. Comparing and contrasting first and second language acquisition: implications for language teachers. English Language Teaching 2(2): 155-163.

Jones, GM, and L Brader-Araje. 2002. The impact of constructivism on education: language, discourse, and meaning. American Communication Journal 5(3): 1-9.

Krashen, S. 1982. Theory versus practice in language training. In Innovative approaches to language teaching, ed. RW Blair, 15-24. Rowley, MA: Newburry House Publishers.

Kumaravadivelu, B. 1994. The postmethod condition: (E) merging strategies for second/foreign language teaching. TESOL Quarterly 28(1): 27-48. http://dx.doi.org/10.2307/3587197.

Larsen-Freeman, D. 2000. Techniques and principles in language teaching, 2nd ed. Oxford: Oxford University Press. LeDoux, J. 1996. The emotional brain. New York, NY: Simon and Schuster.

Long, MH. 1985. Input and second language acquisition theory. In Input in second language acquisition, ed. G Susan and M Carolyn, 377-393. Rowley, MA: Newbury House.

Long, MH. 1996. The role of linguistic environment in second language acquisition. In Handbook of second language acquisition, ed. WC Ritchie and TK Bhatia, 413-468. San Diego: Academic Press.

McLaughlin, B. 1987. Theories of second language learning. London: Edward Arnold.

Messina, JJ. 1999-2004. Tools for early identification and intervention-0-5 years: the "Greenspan" floor time model. http://jamesjmessina.com/earlyintervention/floortime.html. Retrieved August 2013.

Meyer, DL. 2009. The poverty of constructivism. Educational Philosophy and Theory 41(3): 332-341. http://dx.doi.org/ 10.1111/j.1469-5812.2008.00457.x.

Moraru, A, S Mihaea, T Elena Adriana, and F Monica. 2011. Evaluation of a program for developing socio-emotional competencies in preschool children. Procedia - Social and Behavioral Sciences 30: 2161-2164. http://dx.doi.org/ 10.1016/.j.sbspro.2011.10.419.

Murphy, LB. 1974. The individual child. Department of Health, Education, and Welfare, publication no. OCD 74-1032. Washington, DC: U.A. Government Printing Office.

Nelson, K. 1977. Facilitating children's syntax acquisition. Developmental Psychology 13: 101-107. http://dx.doi.org/ 10.1037/0012-1649.13.2.101.

Pavlov, IP. 1927. Conditioned reflexes: an investigation of the physiological activity of thecerebral cortex (trans and ed: G. V. Anrep). London: Oxford University Press.

Peal, E, and W Lambert. 1962. The relation of bilingualism to intelligence. Psychological Monogruph 76(546): 1-23.

Piaget, J. 1926. The language and thought of the child. London: Routledge and Kegan.

Piaget, J. 1962. The stages of intellectual development of the child. In Childhood psychopathology, ed. H Stephen and J McDermott, 157-166. New York: International Universities Press.

Pienemann, M. 1998. Language processing and second language development: processability theory. Amsterdam: John Benjamins.

Pienemann, M (ed.). 2005. Cross-linguistic aspects of processability theory. Amsterdam: John Benjamins.

Pishghadam, R. 2009. A quantitative analysis of the relationship between emotional intelligence and foreign language learning. Electronic Journal of Foreign Language Teaching 6(1): 31-41.

Pishghadam, R, MS Tabatabaeyan, and S Navari. 2013. A critical and practical analysis of first language acquisition theories: the origin and development. Iran, Mashhad: Ferdowsi University of Mashhad Publications.

Rappaport, D. 1960. The structure of psychoanalytic theory: a systematizing attempt. New York: International University Press.

Richards, JC, and TS Rodgers. 2001. Approaches and methods in language teaching. New York: Cambridge University Press. http://dx.doi.org/10.1017/CBO9780511667305.

Salovey, P, and M John. 1990. Emotional intelligence. Imagination, cognition, and personality 9: 185-211. http://dx.doi. org/10.2190/DUGG-P24E-52WK-6CDG.

Seskin, L, F Eileen, T Gil, Y Ruby, K Mark Sossin, and Y Anastasia. 2010. Attachment and autism: parental attachment representations and relational behaviors in the parent-child dyad. J Abnorm Child Psychol 38: 949-960. http://dx. doi.org/10.1007/s10802-010-9417-y.

Shanker, S. 2002. The generativist-interactionist debate over specific language impairment: psycholinguistics at a crossroads. American Journal of Psychology 115(3): 415-450. http://dx.doi.org/10.2307/1423425.

Shanker, S, and SI Greenspan. 2005. The role of affect in language development. Theoria 59: 329-343.

Shanmugasundaram, U, and AR Mohamad. 2011. Social and emotional competency of beginning teachers. Procedia - Social and Behavioral Sciences 29: 1788-1796. http://dx.doi.org/10.1016/.sbspro.2011.11.426.

Siller, M, and M Sigman. 2002. The behaviors of parents of children with autism predict the subsequent development of their children's communication. Journal of Autism and Developmental Disorders 32: 77-89. http://dx.doi.org/ 10.1023/A:1014884404276.

Simpson, RL. 2005. Autism spectrum disorders: interventions and treatments for children and youth. Thousand Oaks, CA: Corwin Press.

Skinner, BF. 1957. Verbal behavior. US: Prentice-Hall, Inc. http://dx.doi.org/10.1037/11256-000.

Stern, HH. 1983. Fundamental concepts of language teaching. Oxford: Oxford University Press.

Tormey, R. 2005. The cost of values: questioning the application of the term in development education. Development Education Journal 11: 9-11.

Tomasello, M. 2003. Constructing a language: a usage-based theory of language acquisition. Cambridge, Mass.: Harvard University Press. 
Vygotsky, LS. 1978. Mind and society: the development of higher psychological processes. Cambridge, MA: Harvard University Press.

Vygotsky, LS. 1986. Thought and language. Cambridge, MA: MIT Press.

Widdowson, HG. 2004. Text, context, and pretext: critical issues in discourse analysis. Oxford: Blackwell. http://dx.doi.org/ 10.1002/9780470758427.

Wieder, S, and SI Greenspan. 2003. Climbing the symbolic ladder in the DIR model through floor time/interactive play. Autism 7: 425-435. http://dx.doi.org/10.1177/1362361303007004008

doi:10.1186/2191-5059-3-9

Cite this article as: Pishghadam et al:: Emotion-Based Language Instruction (EBLI) as a new perspective in

bilingual education. Multilingual Education 2013 3:9.

\section{Submit your manuscript to a SpringerOpen ${ }^{0}$ journal and benefit from:}

- Convenient online submission

- Rigorous peer review

- Immediate publication on acceptance

- Open access: articles freely available online

- High visibility within the field

- Retaining the copyright to your article

Submit your next manuscript at $>$ springeropen.com 